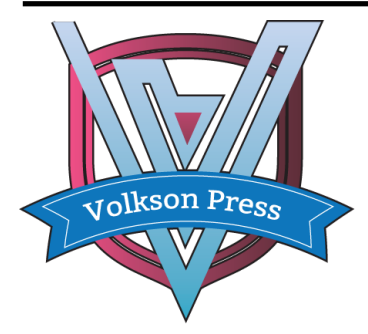

Contents List available at VOLKSON PRESS

New Materials and Intelligent Manufacturing (NMIM)

DOI : http://doi.org/10.26480/icnmim.01.2018.31.35

Journal Homepage: https://topicsonchemeng.org.my/

ISBN: 978-1-948012-12-6

\title{
CONJUGATE HEAT TRANSFER INVESTIGATION ON COOLING PERFORMANCE OF AIR-COOLED TURBINE STATOR BLADE
}

\author{
Su Li-chao' ${ }^{1}$, Shi Jing-cheng ${ }^{1}$, Zhang Jing-yu' ${ }^{2}$, Huang Yong-hui ${ }^{1}$ \\ ${ }^{1}$ Science and Technology on Space Physics Laboratory. \\ ${ }^{2}$ School of Engine and Energy, Northwestern Poly-technical University, Xi'an, China.
}

This is an open access article distributed under the Creative Commons Attribution License, which permits unrestricted use, distribution, and reproduction in any medium, provided the original work is properly cited

\section{ARTICLE DETAILS}

\section{Article History:}

Received 26 June 2018 Accepted 2 July 2018 Available online 1 August 2018

\section{ABSTRACT}

For aero-engines, stator blade is a key component, which is important to increase thermal cycle efficiency. In this paper, a calculation model using conjugate heat transfer (CHT) method was established for an aircraft engine firstlevel turbine stator blade with air cooling, and 3D heat transfer simulation considering the radiative influence was accomplished, which caused the computed results to be more reasonable and accurate. The first-level turbine stator blade channel's flow field temperature distribution and the stator blade surface's temperature distribution were obtained in three different working states: the max-power state, the cruise state and the idle-power state. On this basis, the research to the cooling performance of the turbine air-cooled stator blade was conducted. The results provided the basis for material feasibility analysis of the turbine stator blade, and the calculation method was of high value on engineering application.

\section{KEYWORDS}

Gas turbine, conjugate heat transfer, air-cooled stator blade, cooling performance, radiative influence, material feasibility

\section{INTRODUCTION}

An important way to improve aircraft engine performance is to increase thermal cycle efficiency by improving the turbine inlet temperature $T_{3}^{*}$ and the total compression ratio $\pi_{k}^{*}[1-2]$. According to the calculation, the engine thrust will increase by about $10 \%$ with $T_{3}^{*}$ improving $55 \mathrm{~K}$ in the case of the same engine size. Nowadays the usual aviation gas turbine' $s$ inlet temperature has been as high as $2000 \mathrm{~K}$, which goes far beyond the heat-resistant limit (about 1600K) of the turbine blade material, as shown in Figure 1 [3-4]. Thus, adapting some cooling ways to reduce the blade surface temperature is essential.

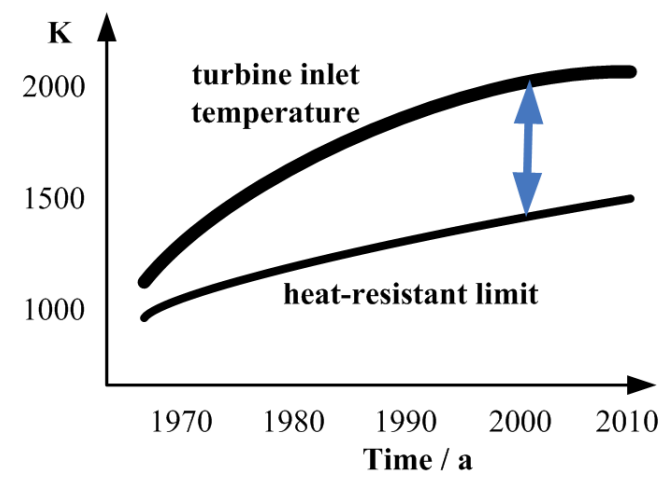

Figure 1: Trend-line of Turbine Inlet Temperature

The turbine blade is a typical complex hot-side structure with high temperature and high load, its performance and reliability are directly related to engine performance, durability, reliability, and life [5]. To make the turbine blade withstand the higher inlet temperature, now the main ways are as follows:
1) Improve the heat resistance of the material, such as developing high performance heat resistant alloy, manufacturing single crystal blades [6];

2) Apply advanced cooling technology, consume a small amount of cooling air to achieve a good cooling performance [7-10].

It is generally considered that the material improvement accounts for about $40 \%$, and cooling technology accounts for $60 \%$ or so. Therefore, how to improve the cooling efficiency and obtain greater cooling effect with less cooling air has always been one of the important issues that aeroengine designers focus on, especially when the design of the turbine blades becomes more and more sophisticated and needs more detailed range of reference. Therefore, understanding the blade flow field temperature distribution and the blade surface temperature distribution is very important.

In this paper, the calculation with conjugate heat transfer (CHT) method aimed at an aircraft engine turbine stator blade was conducted. The flow field of turbine blade channel, temperature distribution and blade surface and internal temperature distribution were obtained in three different working states: the max-power state, the cruise state and the idle-power state. On this basis, the cooling performance of the air-cooled stator blade was analyzed.

\section{OBJECTIVE}

A certain type of aero-engine first-level turbine stator blade is the internal air-cooled blade, considering the characteristics of the turbine internal cooling blade, the computational domain was abstracted into the graphics of Figure 2, in which fluid domain I can be seen as the flow field of the mainstream channel, fluid domain II can be seen as internal cold flow field of blade, and solid domain can be seen as a hollow turbine blade with aircooling [11-12]. 


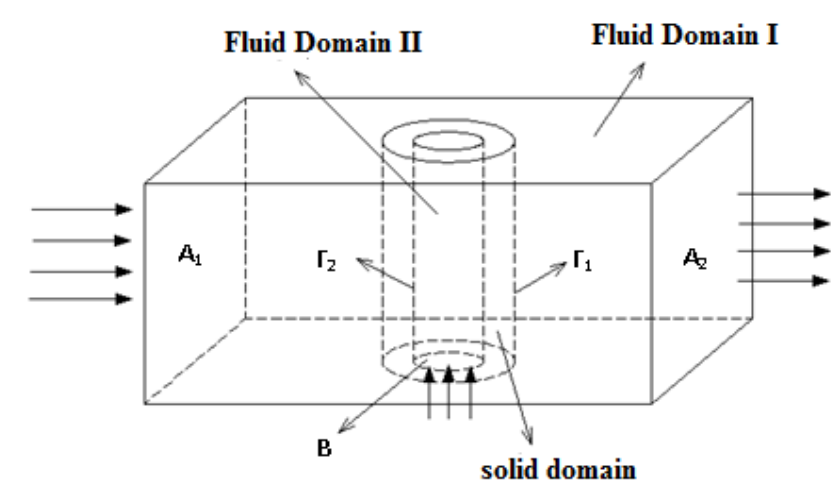

Figure 2: Sketch of Computational Domain

The entire computational domain consists of fluid domain I, fluid domain II and solid domain. $\boldsymbol{\Gamma}_{\mathbf{1}}$ is the interface of the outflow and solid domain, and $\Gamma_{2}$ is the interface of the influx and solid domain. The high-temperature fluid from the outflow channel (Fluid Domain I) transfers heat to solid through $\boldsymbol{\Gamma}_{1}$, and solid transfers heat to influx (Fluid Domain II) through $\boldsymbol{\Gamma}_{2}$. In this paper, the flow field distribution of the outflow channel (Fluid Domain I) and the blade (solid domain) temperature distribution were obtained through conjugate heat transfer numerical simulation method.

\section{MATHEMATICAL MODEL}

In this paper, the computational domain contains both fluid and solid domains, thus it is essential to establish the control equations respectively in the fluid and solid domains. The fluid domain consists of two parts (the mainstream and the secondary flow), which are described by the threedimensional flow. The mainstream is the gas, and the secondary flow is the air flow. Their properties are different, but they are considered as air in a unified way for the convenience. In particular, the following assumptions are considered:

a) The fluid is Newtonian fluid;

b) The fluid is isotropic fluid;

c) The fluid gravity (body force) is neglected.

\subsection{Control Equation}

The fluid three-dimensional unsteady compressible control equations are shown as follows:

The continuity equation

$$
\frac{\partial \rho}{\partial t}+\frac{\partial\left(\rho u_{i}\right)}{\partial x_{i}}=0
$$

The momentum equation

$$
\frac{\partial\left(\rho u_{i}\right)}{\partial t}+\frac{\partial\left(\rho u_{i} u_{j}\right)}{\partial x_{j}}=-\frac{\partial p}{\partial x_{i}}+\frac{\partial \tau_{i j}}{\partial x_{j}}+\rho F_{i}
$$

The energy equation

$$
\frac{\partial(\rho T)}{\partial t}+\frac{\partial\left(\rho u_{i} T\right)}{\partial x_{i}}=\operatorname{div}\left(\frac{k}{c_{p}} \nabla T\right)+S_{T}
$$

Where, $\mathrm{k}$ is the thermal conductivity of the fluid; $c_{p}$ is the specific heat of the fluid; $S_{T}$ is source term, $S_{T}=S_{h}+\Phi, S_{h}$ is internal heat source, $\Phi$ is the dissipation function.

$$
\tau_{i j}=\left[\mu\left(\frac{\partial u_{i}}{\partial x_{j}}+\frac{\partial u_{j}}{\partial x_{i}}\right)\right]+\lambda \delta_{i j} \frac{\partial u_{i}}{\partial x_{i}}
$$

Where, $\mu$ is the fluid dynamic viscosity; $\lambda$ is the second viscosity coefficient, by the Stokes assumption, $\lambda=-\frac{2}{3} \mu ; \delta_{i j}=\left\{\begin{array}{l}0, i \neq j \\ 1, i=j\end{array}\right.$ is the Kronecker symbol.

Considering the coupled heat transfer problem of the blade with the gas flow and cooling airflow, the computational domain is divided into two parts: the fluid region and the coupled heat conduction solid region. In the fluid region, the above control equations are applied to solve the fluid parameters such as pressure, velocity, temperature, etc; while the temperature distribution is only obtained by solving the heat conduction equations in the coupled heat conduction solid region.

The heat conduction equation for the solid domain

$$
\frac{\partial(\rho c T)}{\partial t}=\frac{\partial}{\partial x_{j}}\left(k_{S} \frac{\partial T}{\partial x_{j}}\right)+S_{T}
$$

Where, $\mathrm{c}$ is the solid specific heat; $\mathrm{K}_{\mathrm{S}}$ is the solid thermal conductivity; $\mathrm{S}_{\mathrm{T}}$ is the solid internal energy heat source.

\subsection{Radiation Model}

With the improvement of the turbine inlet temperature, the radiation heat flux has become the heat source that increasingly cannot be neglected. In this paper, the influence of the radiation heat flux was considered when the turbine blade temperature was calculated. The P-1 radiation model was applied to conduct radiation heat flow calculation, which is the simple type of the P-N model. The P-N model is to expand the radiation intensity to the orthogonal spherical harmonics, and the P-1 model only takes the first four terms of the orthogonal spherical harmonics. The radiation heat flux $q_{r}$ is shown as follows.

$$
r=-\frac{1}{3\left(a+\sigma_{s}\right)-C \sigma_{s}} \Delta G_{1}
$$

Where, $\mathrm{G}$ is the incident radiation; $\mathrm{c}$ is linear anisotropic phase function Coefficient; a is the absorption coefficient; $\sigma_{s}$ is the scattering coefficient.

\section{CFD METHODOLOGY}

\subsection{Model Establishment}

As mentioned in the objective, the numerical model includes two parts: the fluid domain and the solid domain, in which the fluid domain is divided into the external gas channel and internal cooling flow channel. The domain is shown in Figure 3. 

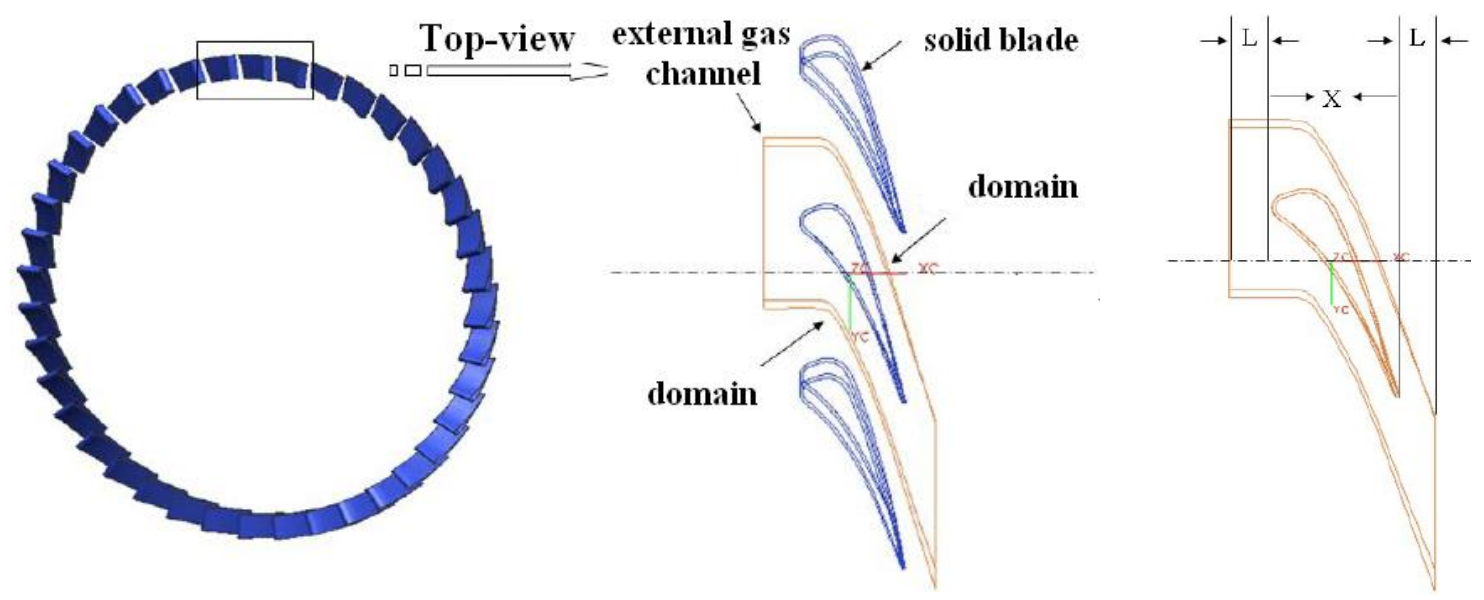

(a)

(b)

Figure 3: Schematic of the External Fluid Domain

Figure 3(a) shows the boundary of the external fluid domain, figure 3(b) describes the main area parameters in the gas flow direction. Here, $\mathrm{L}$ is the distance from blade leading edge to channel inlet face, and also is the distance from blade trailing edge to channel outlet face; $\mathrm{X}$ is the projection length of the blade chord in the engine axis. In accordance with the experience of the impeller machine modeling, $\mathrm{L}$ is generally $1 \sim 2$ times $\mathrm{X}$ in the length, this article takes 1.5 times.

\subsection{Computational Meshes}

As can be seen, the turbine guide vane is an irregular space-form of complex shape, non-structured mesh has good adaptability, so this article adopts non-structured mesh to partition the model. To ensure that the first layer of the meshes is in the bottom of the boundary layer, we especially appropriately increase the boundary layer mesh. At the meantime, some main heat-exchange areas are increased, such as blade leading edge, turbulence ribs, turbulence column, gas film hole and etc. For this design, the full three-dimensional model had 6.75 million meshes.

\subsection{Boundary Conditions}

The boundary conditions are shown in Figure 4. The inlet face of the external fluid channel is pressure boundary, static temperature and direction are given ; and the outlet face is mass flow boundary, the mass flow is defined by gas flow and cooling air. The inlet of the internal cooling channel is mass flow boundary, the cooling air mass flow and static temperature are given. While, the left and right surfaces of the external fluid channel are modeled as periodic; the upper and lower surface of the external flow channel are modeled as walls, we assume that it is adiabatic and no-slip.

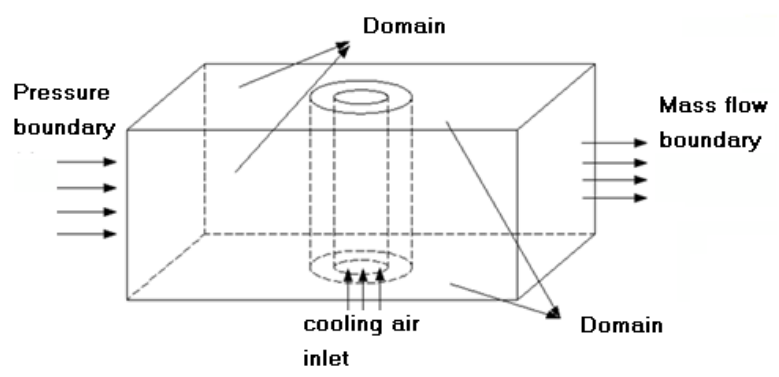

Figure 4: Schematic of Boundary Conditions

\section{RESULTS}

\subsection{Temperature Distribution of the External Fluid Channel}

The lower limit of temperature under the max-power state is set at $1150^{\circ} \mathrm{C}$ under the max-power state, $920^{\circ} \mathrm{C}$ under the cruise state and $700^{\circ} \mathrm{C}$ under the idle-power state. The temperature distributions of external fluid channel under three working-states are considered and shown in Figure 5.

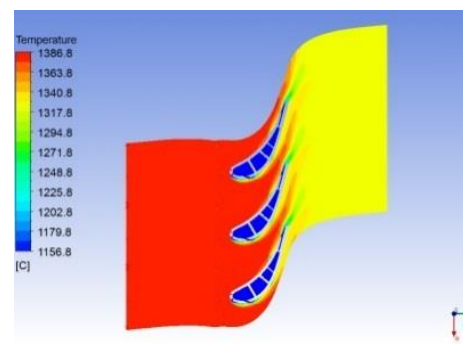

(a) $10 \%$ of the blade height

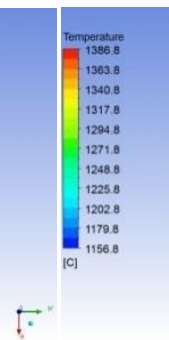

(b) $50 \%$ of the blade height

A the max-power state

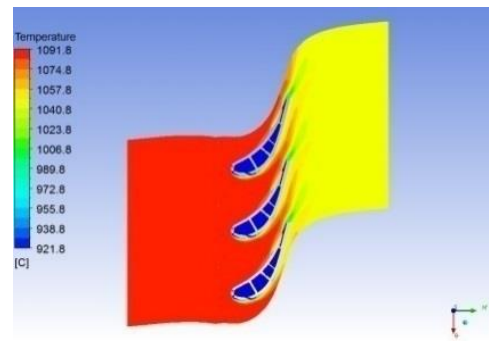

(a) $10 \%$ of the blade height

(b) $50 \%$ of the blade height
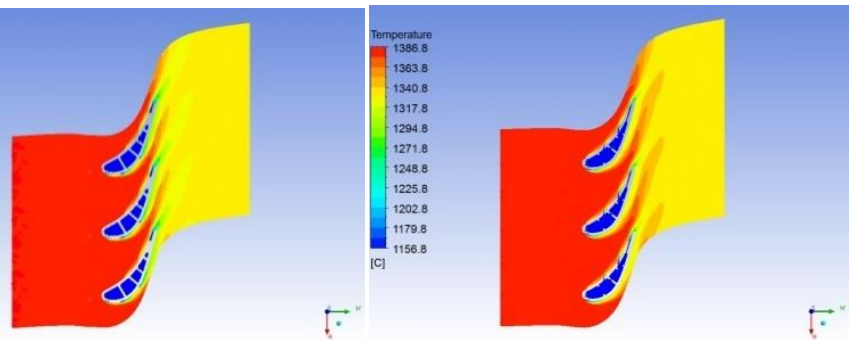

(c) $90 \%$ of the blade height

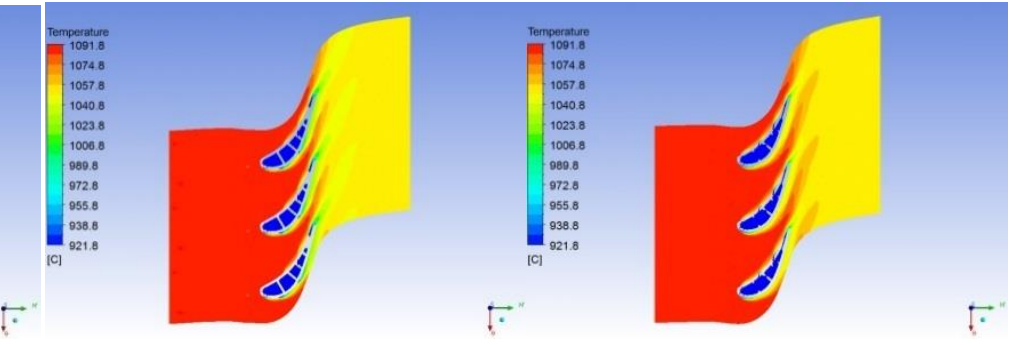

(c) $90 \%$ of the blade height

B the cruise state 


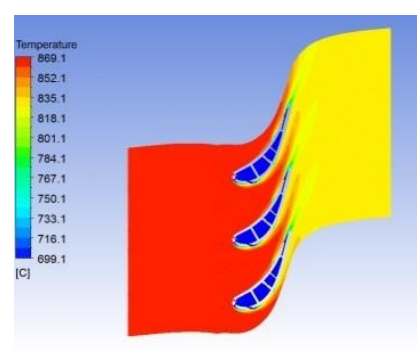

(a) $10 \%$ of the blade height

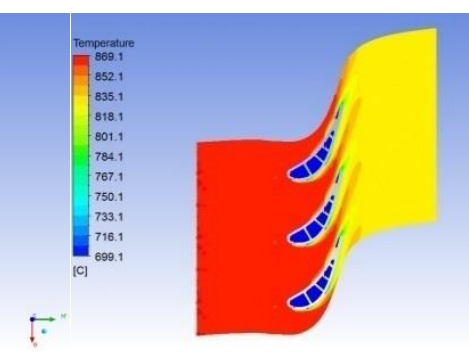

(b) $50 \%$ of the blade height

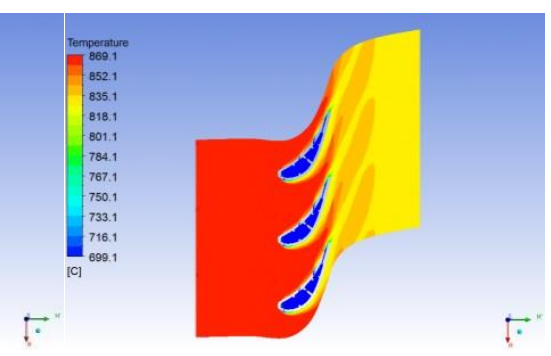

(c) $90 \%$ of the blade height

$\mathrm{C}$ the idle-power state

Figure 5: The Temperature Distributions of External Fluid Channel

Based on the simulation results, it can be seen that the maximum temperature appears in the max-power state, and the temperature distributions of the three working-states are similar, they have some common features. The temperature gradually reduces from inlet to outlet, there exists the maximum gradient near the throat. The temperature around the blade is lower, that is mainly due to the film cooling holes which are distributed in the blade basin and the blade dorsal. The cooling air discharged from those cooling holes separates the blade form the hightemperature burning gas, thus protects the blades. At the trailing edge of the blade, there exists a long and narrow lower temperature area, which is mainly caused by cooling air discharge from the trailing edge seam.

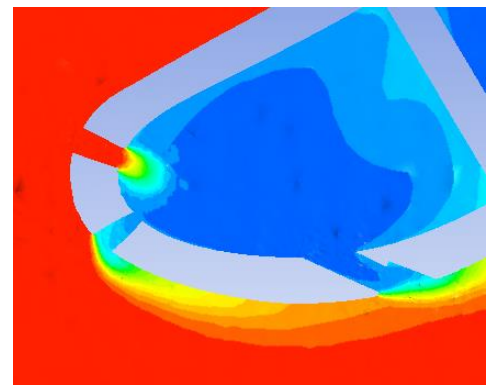

(a) $10 \%$ of the blade height

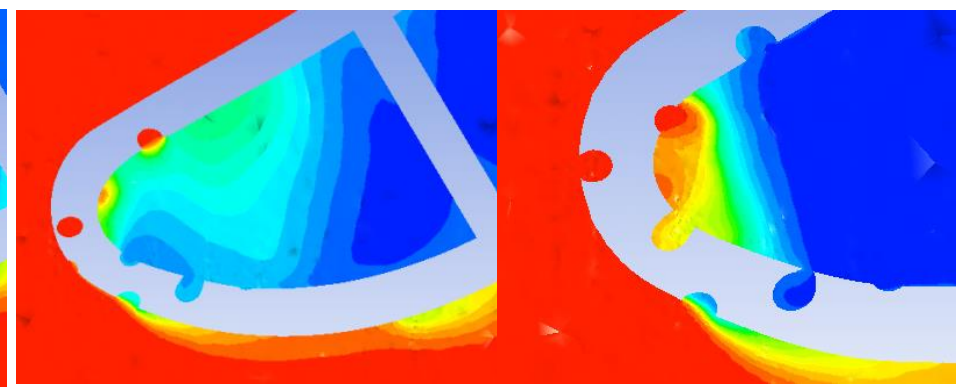

(b) $50 \%$ of the blade height

(c) $90 \%$ of the blade height

Figure 6: The Partial Enlargement of the Blade Leading Edge

Fig.6 shows the partial enlargement of the blade leading edge under the max-power state. The temperature of a little piece of blade is higher near the leading-edge position. This is mainly because of the high-pressure burning gas, its pressure is higher than the cooling air in the internal cooling channel, this situation may cause the burning gas conversely flow into the cooling air channel, then the cooling effect might be bad in the leading edge of the blade.

\subsection{Cooling Effectiveness}

Contrasting the temperature distribution of the channel with the vane surface, we can get the engine cooling effect in each state as shown in the following table. In this table, the cooling effectiveness, which shows the temperature reduction, is the difference between the gas inlet temperature and the blade average temperature.

Table1: Cooling Effectiveness of the Stator Blade $\left({ }^{\circ} \mathrm{C}\right)$

\begin{tabular}{|c|c|c|c|c|c|c|}
\hline \multirow{3}{*}{ Working state } & \multicolumn{5}{|c|}{ temperature } & \multirow{3}{*}{$\begin{array}{l}\text { Cooling } \\
\text { Effectiveness }\end{array}$} \\
\hline & \multirow{2}{*}{ Gas inlet } & \multirow{2}{*}{ Gas outlet } & \multicolumn{3}{|c|}{ Blade surface } & \\
\hline & & & $\begin{array}{l}\text { vane } \\
\text { basin }\end{array}$ & vane dorsal & $\max$ & \\
\hline The max-power state & 1460 & 1380 & 1130 & 1120 & 1234 & 226 \\
\hline The cruise state & 1100 & 1040 & 870 & 865 & 945 & 155 \\
\hline The idle-power state & 880 & 830 & 690 & 685 & 760 & 120 \\
\hline
\end{tabular}

From the table, we can see that the solid blade temperature of blade basin and blade dorsal are similar, that is because the blade dorsal adapted more film cooling holes, so the cooling effect of blade dorsal is better. The cooling effect under the max-power working condition is best, for the temperature decreases the most.

\section{CONCLUSIONS}

1) This article concentrates on the cooling effectiveness simulation of the air-cooled turbine stator blade, which has a remarkable impact on the engine performance. The radiation influence was accomplished, which causes the computed results to be more reasonable and accurate.

2) Through the analysis of the external fluid channel temperature distribution, we can find the temperature of the external fluid channel reduces $50^{\circ} \mathrm{C} \sim 80{ }^{\circ} \mathrm{Caveragely,} \mathrm{due} \mathrm{to} \mathrm{the} \mathrm{cooling} \mathrm{air} \mathrm{from} \mathrm{film} \mathrm{cooling}$ holes. The temperature reduction under max-power working state is the most appearance.

3) Comparing the gas inlet temperature and the blade average temperature, the cooling effectiveness under three different workingconditions are calculated and contrasted. The max temperature reduction reaches $226^{\circ} \mathrm{C}, 155^{\circ} \mathrm{C}, 120^{\circ} \mathrm{C}$ respectively.

\section{ACKNOWLEDGEMENT}

This research was accomplished under the guidance of Mr Liu Zhen-xia. We thank Ren-zhong for his insightful research and discussions, we also thank the many people who helped with building the model and running the experiments, with a special thanks to Zhang Jing-yu. 


\section{ABOUT THE AUTHORS}

Su Li-Chao,male,born Born in August 1985,Aerospace propulsion theory and engineering, graduated from NWPU,working for Science and Technology on Space Physics Laboratory.

\section{REFERENCES}

[1] Shun-zhou, H., Jun, H., He-pu, J. 2006. Investigation of core engine and derivative aero-engine development [J]. Journal of Aerospace Power, 21 (2), 241-247.

[2] Wen-feng, X., Hui-ren, Z., Li, Z. 2008. Study on engineering method for coupled calculation of temperature distribution in air-cooling turbine blade [J]. Turbine Technology, 50 (3), 201-203.

[3] Ping, D. 2009. Research on conjugate heat transfer simulation of aero turbine engine air-cooled vane [D]. Harbin: Harbin Institute of Technology.

[4] Kumar, N.A., Kale, S.R. 2002. Numerical simulation of steady state heat transfer in a ceramic-coated gas turbine blade [J]. International Journal of Heat and Mass Transfer, 45 (24), 4831-4845.

[5] Lu, Y., Allison, D., Ekkad, S.V. 2003. Turbine blade showerhead film cooling: Influence of hole angle and shaping. International Journal of Heat and Fluid Flow, 28 (5), 922-931.

[6] Hua, Q., He-fu, W., Wei-dong, W. 2008. Optimization design of crystallographic orientation in single crystal turbine blade [J]. Journal of Aerospace Power, 23 (12), 2184-2189.

[7] Jun, H., Song-tao, W., Zhong-qi, W. 2012. Development of the turbine with cooling air injection [J]. Energy Conservation Technology, 30 (1), 2933.

[8] An-ding, X., Song-ling, L., Hui-ren, Z. 2004. A new model for film cooling effectiveness computation on blade surface in a turbine cascade [J]. Journal of propulsion technology, 25 (4), 303-306.

[9] Jiang-tao, B., Hui-ren, Z., Zong-wei, Z. 2010. Measurements of heat transfer coefficient and film cooling effectiveness distribution on a vane using transient liquid crystal technique [J]. Journal of XI'AN Jiao-tong University, 44 (11), 92-97.

[10] Qiang, W., Zhao-yuan, G., Chi, Z. 2011. Coupled heat transfer simulations of an air- cooled turbine with single cooling channel [J]. Journal of Aerospace Power, 26 (1), 78-84.

[11] Zhen-xia, L., Li-fen, Z. 2007. Numerical study of heat transfer using heat-flow coupling method for turbine blade with air cooling [J]. Journal of Northwestern Poly-technical University, 25 (2), 315-319.

[12] Li-fen, Z., Zhen-xia, L., Xiao-chun, L. 2007. Numerical study of 3D heat transfer for turbine blade with air cooling [J]. Journal of Aerospace Power, 22 (8), 1268-1272.

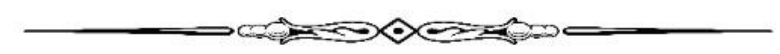

